\title{
Identifying the Mechanical Parameters of Hard Coating with Strain Dependent Characteristic by an Inverse Method
}

\author{
Wei Sun, Zhuo Wang, Mingwei Zhu, and Guangyu Du \\ School of Mechanical Engineering \& Automation, Northeastern University, Shenyang 110819, China \\ Correspondence should be addressed to Wei Sun; ddsunwei@126.com
}

Received 10 April 2015; Accepted 7 July 2015

Academic Editor: Alicia Gonzalez-Buelga

Copyright ( 2015 Wei Sun et al. This is an open access article distributed under the Creative Commons Attribution License, which permits unrestricted use, distribution, and reproduction in any medium, provided the original work is properly cited.

\begin{abstract}
The mechanical parameters of hard coating, such as storage modulus and loss factor, are affected by preparation technology significantly and have the strain dependent characteristic. So the effective identification of these mechanical parameters becomes a challenge task. In this study, a hard-coating cantilever thin plate under base excitation was taken as the research object, and an inverse method was developed to identify these mechanical parameters. Firstly, the principles of identifying storage modulus and loss factor of hard coating were presented according to the inverse method. Then, from the need of parameters identification, the analytical model and calculation formula of equivalent strain for the hard-coating composite plate were derived. Next, also for parameter identification, the vibration experiments about the cantilever plate coated with NiCoCrAlY+ yttria-stabilised zirconia (YSZ) hard coating were performed. Finally, the mechanical parameters of NiCoCrAlY+YSZ hard coating with strain dependent characteristic were identified by the proposed method. The identification results show that the change rules of storage modulus and loss factor of hard coating with the strain amplitude are almost consistent with the results listed in the other similar references. However, the identification results herein can more directly serve for the dynamic modeling of hard-coating plate-shape composite structure.
\end{abstract}

\section{Introduction}

Hard coating is a kind of coating materials prepared by the metal substrate, ceramic substrate, or their mixtures and is mainly used in barrier coatings [1] and antifriction [2] and antierosion [3] coatings. Recent studies have shown that the hard coating can reduce the resonant stress of thin shell component under the high temperature and strong corrosion environments, so the researches on hard-coating damping vibration have received increasing attention [4-6]. To better implement the hard-coating damping vibration, it is necessary to create a dynamics analysis model of hard-coating composite structure and realize the effective prediction and design of damping performance of hard coating, while the premise of creating this model is obtaining the mechanical parameters of hard coating, such as storage modulus (Young's modulus) and loss factor.

It has been shown by a number of researchers [79] that hard coating has the strain dependent characteristic; that is, the storage modulus and loss factor of hard coating can change with the strain response amplitude of composite structure. The strain dependent characteristic of hard coating also makes the coated structure produce the nonlinear vibration characteristics of variable stiffness and damping. In addition, the mechanical parameters of hard coating are affected by preparation technology significantly; in other words, even for the coating materials with the same composition, the mechanical parameters of hard coating will be various for the different preparation technologies. For example, Patsias et al. [10] tested the mechanical parameters of a hard coating prepared by air plasma spraying (APS) and electron beam physical vapor deposition (EB-PVD), respectively, and they found that the obtained mechanical parameters are significantly different for the two preparation technologies. Because of the abovementioned characteristics of hard coating, the identification of hard-coating mechanical parameters becomes a challenge and an urgent task.

Now, some scholars have proposed several methods to identify the mechanical parameters of hard coating. In general, these methods can be classified into three classes, 
and they are the indentation method [11], bend tests method [12], and vibration tests method [7-9, 13-17], respectively. Because the equipment is simple and easy to operate, the vibration tests method has been widely used recently. For the vibration tests method, a more frequently used method is the identification technology based on Oberst beam theory; the American Society for Testing and Materials (ASTM) [13] has adopted the technology as a standard method for determining the material properties of coatings. Patsias et al. [14] adopted this Oberst beam approach to identify the mechanical parameters of a hard coating and they tested the vibration decay response of cantilever beam specimen with and without coating and used these data to extract the storage modulus and loss factor with strain dependent characteristic. Another vibration tests method is also based on beam theory. Torvik [7] deduced the rules of energy storage and energy dissipation for the uncoated and coated beams, used the high order polynomial to describe the coating parameters, and then realized the identification of the mechanical parameters.

Among the vibration tests methods, there is also an important method. The method applies an experimentalnumerical procedure and utilizes the minimizing difference between the theoretically and experimentally determined natural frequencies and vibration response to extract the mechanical parameters of coating material, so the method is named as inverse method. The inverse method has been wildly used for the identification of viscoelastic material parameters $[15,16]$. For the identification of hard-coating material, there are also several researchers to demonstrate the method. For example, Reed et al. [8] tested the titanium beam coated with hard coating in free-free boundary status and adopted the inverse method to determine the mechanical parameters of magnesium aluminate spinel hard coating. Easterday et al. [17] also depended on the free-free boundary beam and used the inverse method to obtain the mechanical parameters of YSZ hard coating under different temperatures. Different with abovementioned boundary conditions, Tassini et al. [9] adopted a cantilever beam coated with hard coating to practice the inverse method.

All the above studies about identification of mechanical parameters of hard coating are of benefit to understand the constitutive model and damping mechanism of hard coating and dynamic mechanism of hard-coating composite structure. However, all of these studies focus on beam-shape specimen to identify the mechanical parameters of hard coating. Because the mechanical parameters of hard coating are affected by preparation technology significantly, maybe, it is unreliable to create the dynamics model of nonbeam structure using the identification results obtained by beamshape specimen. In fact, a more potential application of hardcoating damping is for turbomachinery blades and a $2 \mathrm{D}$ hard-coating plate structure model can describe the vibration reduction mechanism of blade effectively. Correspondingly, the hard-coating parameters obtained from a plate-shape specimen can more directly serve for this modeling. Therefore, in this work, a cantilever thin coated plate was chosen as study object and the inverse method was also adopted to identify the mechanical parameters of hard coating. In addition, the analytical model of hard-coating plate was created and used to extract the hard-coating mechanical parameters in the developing method.

This paper is organized as follows. In Section 2, based on the cantilever thin plate structure and considering the strain dependent characteristic of hard coating, the principles of identifying storage modulus and loss factor of hard coating were presented according to inverse method. In Section 3, from the need of identifying the mechanical parameters of hard coating, the analytical model and the calculation formula of equivalent strain for the hard-coating composite plate were derived based on classical thin plate theory, and the rationality of developed analytical model was also verified by commercial finite element software. In Section 4, the vibration experiment about the cantilever plate coated with NiCoCrAlY + YSZ hard coating was performed and some important dynamics characteristic parameters, such as natural frequencies, damping ratios, and resonant responses, were obtained, which are necessary data for using the inverse method. In Section 5, the mechanical parameters of NiCoCrAlY + YSZ hard coating with strain dependent characteristic were identified by the proposed method. Some important results of this study were listed in Section 6.

\section{Identification Principle of the Proposed Inverse Method}

The hard-coating mechanical parameters with strain dependent characteristic can be expressed as

$$
E_{c}^{*}\left(\varepsilon_{e}\right)=E_{c R}\left(\varepsilon_{e}\right)\left[1+i \eta_{c}\left(\varepsilon_{e}\right)\right],
$$

where $E_{c}^{*}\left(\varepsilon_{e}\right)$ is the complex modulus of the hard coating and $*$ refers to complex value. For simplicity, only material parameters are marked with complex value in this paper, $\varepsilon_{e}$ is the equivalent strain, and $E_{c R}\left(\varepsilon_{e}\right)$ and $\eta_{c}\left(\varepsilon_{e}\right)$ are the storage modulus and loss factor, respectively. Based on the inverse method and taking the hard-coating cantilever thin plate as a study object, the identification principle of storage modulus and loss factor of hard coating will be presented in the following.

\subsection{Identification Principle of Storage Modulus of Hard} Coating. The storage modulus of hard coating has a direct influence on the resonant frequency of composite plate, and thus the storage modulus can be reversely derived by comparing the theoretically and experimentally determined resonant frequency. To describe the storage modulus with strain dependent characteristic, the hard-coating thin plate should be excited by different excitation levels and then the different strain response amplitudes can be obtained. The whole procedure of identifying storage modulus is shown in Figure 1.

It can be seen in Figure 1 that the upper part is vibration tests for the hard-coating composite plate, the lower part is the theoretical modeling and analysis of hard-coating composite plate, and the middle part is the match calculation between theoretical and experimental values by using the model updating technology $[18,19]$. Performing the three 


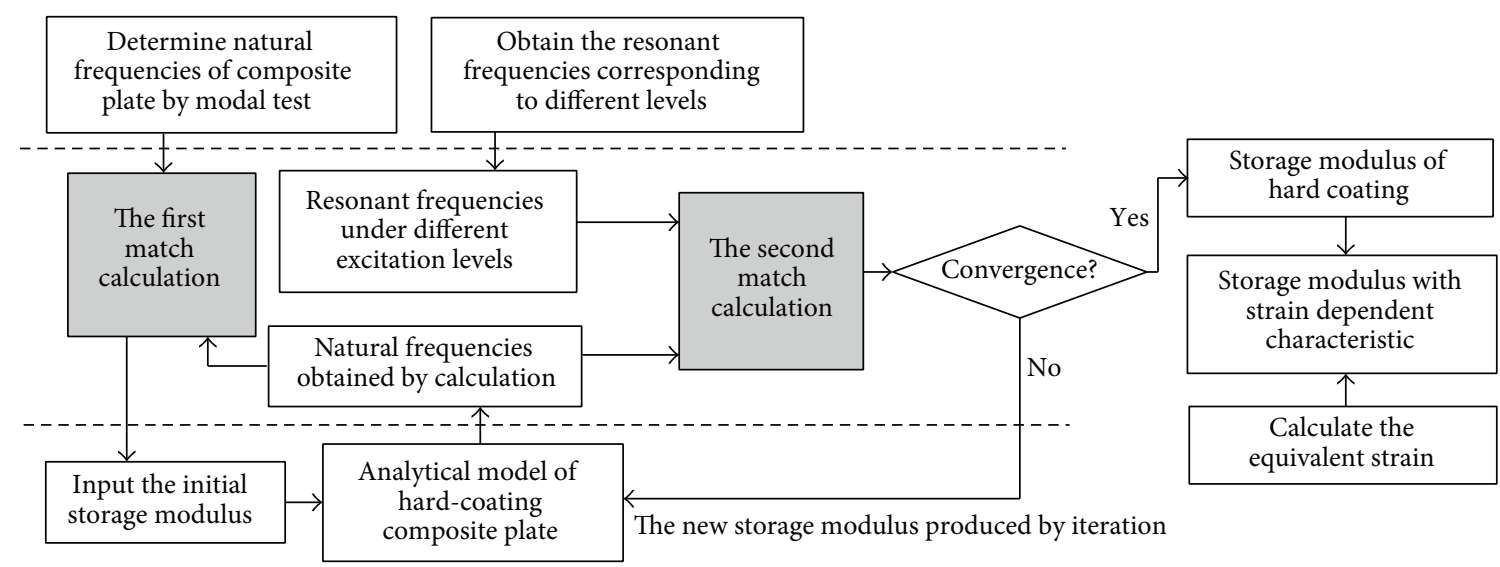

FIGURE 1: Identification procedure of storage modulus of hard coating based on the inverse method.

parts contents, the storage modulus of hard coating can be obtained reversely. For the vibration tests part, firstly, hammering method or steady-state test under small excitation level should be adopted to obtain the natural frequencies of coated plate in the considered frequency range, and those natural frequencies can be used as the reference for determining the initial value of hard-coating storage modulus. Then, choosing a specific order and setting a frequency range that included the selected-order natural frequency, sweeping tests are performed under different excitation levels, which can obtain the resonant frequencies corresponding to these excitation levels. In the theoretical modeling part, it contains the analytical modeling of hard-coating composite plate and solution of equivalent strain and these contents will be presented in Section 3.

Notably, there are two times of match calculation between theoretical and experimental values in Figure 1. The goal of the first match calculation is to get the relatively accurate initial value of hard-coating storage modulus, which can save calculation time of identifying the final storage modulus. The match objects of the first match calculation are the measured multiple orders natural frequencies and the corresponding natural frequencies obtained by calculation. The intention of the second match calculation is performing the identification of final hard-coating storage modulus corresponding to the selected order under different excitation levels. The match objects of this match calculation are the measured resonance frequency and the corresponding natural frequency obtained by calculation. These match calculations are realized by the model updating technology, and the following will be given a detailed description.

Let $E_{c R}$ be the storage modulus of hard coating and it is also the design variable in model updating technology. The sensitivity $S_{E, n}$ of the $n$-order eigenvalue $\lambda_{n}$ of hard-coating composite plate to the design variable $E_{c R}$ can be expressed as

$$
S_{E, n}=\frac{\partial \lambda_{n}}{\partial E_{c R}}=\boldsymbol{\varphi}_{n}^{T}\left(\frac{\partial \mathbf{K}}{\partial E_{c R}}-\lambda_{n} \frac{\partial \mathbf{M}}{E_{c R}}\right) \boldsymbol{\varphi}_{n},
$$

where $\boldsymbol{\varphi}_{n}$ is the $n$-order modal shape of composite plate and $\mathbf{K}$ and $\mathbf{M}$ are the stiffness matrix and mass matrix, respectively.
Furthermore, the relationship between eigenvalue and natural frequency can be described as

$$
\lambda_{n}=\left(2 \pi f_{n}\right)^{2},
$$

where $f_{n}$ is the $n$-order natural frequency of composite plate and the unit is $\mathrm{Hz}$.

The objective function of model updating technology can be defined by least square method; that is,

$$
r_{E, n}=\lambda_{e, n}-\lambda_{a, n}=S_{E, n} \Delta E_{c R}
$$

where $r_{E, n}$ is the residual of the $n$-order eigenvalue, $\lambda_{e, n}$ and $\lambda_{a, n}$ are the $n$-order eigenvalue obtained by experiment and analysis, respectively, and $\Delta E_{c R}$ is the variation of storage modulus.

For the first match calculation, due to involving multiple orders, the objective function can be defined as

$$
\operatorname{Min}\left\|\mathbf{S} \Delta E_{c R}-\mathbf{r}\right\|^{2}
$$

where $\|\cdot\|$ refers to solving 2-norm, $\mathbf{S}$ is sensitivity vector obtained by the sensitivity of each considered order eigenvalue to design variable, and $\mathbf{r}$ is the residual vector between the measured eigenvalues and the values obtained by analytical calculation.

Furthermore, if the minimum change amount of design variable is also requested, then (5) can be changed as

$$
\operatorname{Min}\left(\left\|\mathbf{S} \Delta E_{c R}-\mathbf{r}\right\|^{2}+\left|W_{E} \Delta E_{c R}\right|^{2}\right),
$$

where $W_{E}$ is the correction weighted coefficient and the range is from 0 to 0.3 . When the design variable is not sensitive, high value of $W_{E}$ is needed and the high value of $W_{E}$ also means more times of iteration.

In (6), if we solve the derivative about $\Delta E_{c R}$ and let the obtained derivative value be equal to zero, then the following iteration formula about design variable can be yielded:

$$
E_{c R, j}=E_{c R, j-1}-\left(\mathbf{S}^{T} \mathbf{S}+W_{E}\right)^{-1} \mathbf{S}^{T} \mathbf{r}
$$

where $E_{c R, j-1}$ refers to the hard-coating storage modulus gotten from the $(j-1)$ th iteration and $E_{c R, j}$ refers to 


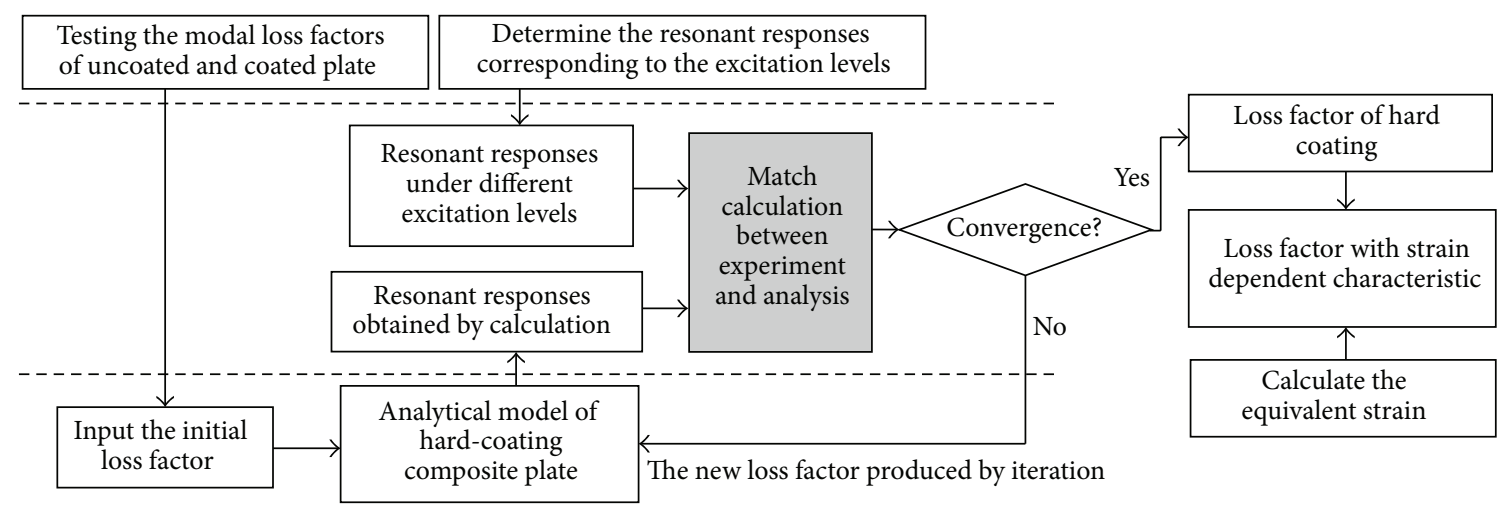

FIGURE 2: Identification procedure of loss factor of hard coating based on the inverse method.

the newer storage modulus obtained by the $j$ th iteration which is more close to experiment value. In this study, the convergence criterion of the first match calculation was described as follows: the difference between the considered orders natural frequencies obtained by analytical calculation and the relative measured values is less than $1 \%$. According to this convergence criterion, the initial storage modulus of hard coating can be obtained after several times of iterations.

Similar to the first match calculation, the objective function of the second match calculation can be defined as

$$
\operatorname{Min}\left(\left|S_{E, n} \Delta E_{c R}-r_{E, n}\right|^{2}+\left|W_{E} \Delta E_{c R}\right|^{2}\right)
$$

and the corresponding iteration formula is

$$
E_{c R, j}=E_{c R, j-1}-\left(S_{E, n}^{2}+W_{E}\right)^{-1} S_{E, n} r_{E, n} .
$$

Because the second match calculation only involves a certain order and a reasonable initial value of storage modulus has been determined, the higher convergence accuracy can be set. Here, the convergence criterion was set as follows: the difference between the considered order natural frequency obtained by analytical calculation and the relative measured value is less than $0.001 \%$. Then, after several times of iteration, the storage modulus corresponding to the certain strain response amplitude can be extracted.

\subsection{Identification Principle of Loss Factor of Hard Coating.} The loss factor of hard coating has a direct influence on the resonant response of composite plate, and thus the loss factor can be reversely derived based on the minimization of the experimental and numerical resonant responses. Similarly, to describe the loss factor with strain dependent characteristic, the different excitation levels are also needed in this identification. The whole procedure about identification of hardcoating loss factor is shown in Figure 2.

In Figure 2, similar to the identification procedure of storage modulus, the upper part is the test of resonant responses and modal loss factors, the lower part is the solution of resonant responses based on analytical method, and the middle part is the match calculation between experimental and theoretical values used in the model update technology. However, compared with the identification of hard-coating storage modulus, there are three contents that should be further considered.

Firstly, obtaining the storage modulus of hard coating accurately is the premise of identifying the loss factor of hard coating, because the obtained storage modulus of hard coating should be input into the analytical model of hardcoating plate. Additionally, there are two kinds of damping in the response calculation of hard-coating plate: one is the material damping of hard coating and the other is the remaining equivalent viscous damping which has excluded the contribution of hard-coating material damping.

Next, the initial value of loss factor also needs to be determined scientifically, because it can reduce the iteration times of match calculation. Here, the initial value of loss factor was determined by comparing the modal loss factor of uncoated and coated cantilever plate. For a certain order, the initial value of loss factor can be calculated according to the following formulas $[7,8]$ :

$$
\begin{aligned}
& \eta_{c}=\frac{\eta(\widehat{R}+1)-\eta_{s}}{\widehat{R}}, \\
& \widehat{R}=\frac{f^{2}}{f_{s}^{2}}\left(1+\frac{H_{c} \rho_{c}}{H_{s} \rho_{s}}\right)-1,
\end{aligned}
$$

where $\eta_{c}, \eta$, and $\eta_{s}$ are the modal loss factor of hard coating, composite plate, and metal substrate, respectively, $\widehat{R}$ is the storage energy ratio between hard coating and substrate, $f$, $f_{s}$ are the natural frequency of coated and uncoated thin plate, $H_{c}, H_{s}$ are the thickness of hard coating and substrate, respectively, and $\rho_{c}$ and $\rho_{s}$ are the density of hard coating and substrate, respectively.

At last, the match calculation in the procedure of identifying loss factor should be further explained. Here, the sensitivity $S_{\eta, n}$ of resonant response to the loss factor (design variable) was obtained by difference method, and the solution formula is

$$
S_{\eta, n}=\frac{\Delta d_{n}}{\Delta \eta_{c}}
$$

where $\Delta d_{n}$ is the variation of the $n$-order resonance response caused by the variation of design variable $\eta_{c}$ and $\Delta \eta_{c}$ is the variation of design variable and also called perturbation step. 


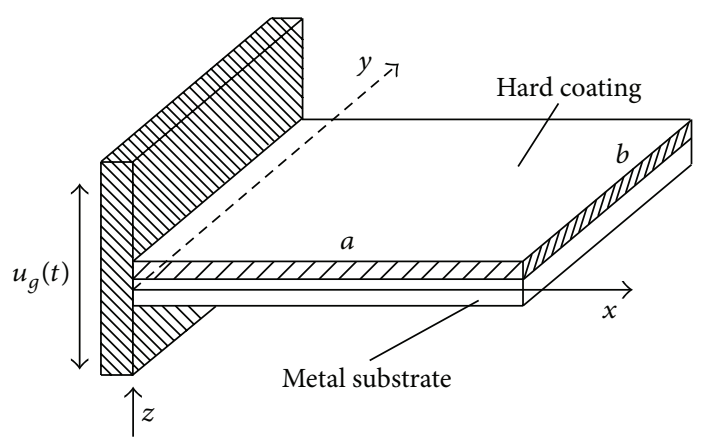

(a) Hard-coated composite plate

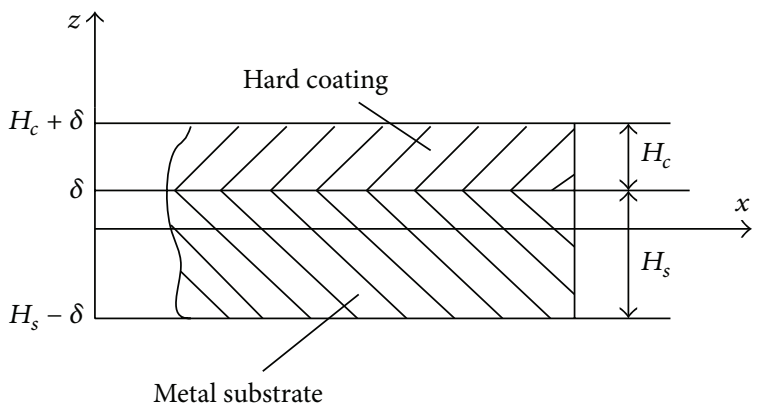

(b) Cross section of composite plate

Figure 3: Hard-coated composite plate under base excitation.

In this study, the perturbation step $\Delta \eta_{c}$ is set as $10^{-4} \times \eta_{c}$ and the reason of choosing this value is based on a stability analysis; that is, when the perturbation step is taken from $10^{-6} \times \eta_{c}$ to $10^{-2} \times \eta_{c}$, the sensitivity coefficients can maintain stability and convergence.

Because the procedure of identifying loss factor of hard coating also involves only a certain order, the objective function and the iteration formula can be determined referring to the second matching calculation in the identification of hardcoating storage modulus. The details are shown as follows. The objective function can be defined as

$$
\operatorname{Min}\left(\left|S_{\eta, n} \Delta \eta_{c}-r_{\eta, n}\right|^{2}+\left|W_{\eta} \Delta \eta_{c}\right|^{2}\right)
$$

where $r_{\eta, n}$ is the residual of the $n$-order resonant response and is expressed as $r_{\eta, n}=d_{e, n}-d_{a, n}$, and accordingly, $d_{e, n}$ and $d_{a, n}$ are the $n$-order resonant response obtained by experiment and analysis, respectively, and $W_{\eta}$ is the correction weighted coefficient of loss factor. And the iteration formula can be defined as

$$
\eta_{c, j}=\eta_{c, j-1}-\left(S_{\eta, n}^{2}+W_{\eta}\right)^{-1} S_{\eta, n} r_{\eta, n}
$$

where $\eta_{c, j-1}$ refers to the loss factor obtained by the $(j-1)$ th iteration calculation and $\eta_{c, j}$ refers to the newer loss factor obtained by the $j$ th iteration. Similarly, this match calculation involves only a certain order and a reasonable initial value of loss factor has been gotten, so the higher convergence accuracy can also be set. Here, the convergence criterion was set as follows: the difference between the considered order resonant response obtained by analytical calculation and the relative measured value is less than $0.01 \%$. Then, after several times of iteration, the loss factor corresponding to the certain strain response amplitude can be obtained.

\section{Analytical Dynamics Model of Hard-Coating Thin Plate}

In this section, referring to classic thin plate theory, energy method was adopted to create the analytical model of hardcoating cantilever thin plate under base excitation. The boundary condition of this model is consistent with experiment which will be described in Section 4, so the created model can capture the measured vibration characteristics of hard-coating cantilever thin plate. Although the material nonlinearity of hard coating makes the composite plate become a nonlinear dynamic system, one can think that the linear model can still be acceptable due to the weak dependency of the material properties with the strain under small excitation level. Therefore, only the linear analytical dynamics model was developed in this study. In fact, in the previous studies $[8,9]$ using inverse method, the linear dynamics model, such as the linear FE model, was also created and used to identify the mechanical parameters of hard coating.

3.1. Analytical Model. A cantilever thin plate coated with hard coating on one side is shown in Figure 3(a) and let $x y$ coordinate plane locate in the neutral surface of composite plate. The length of plate is $a$ and the width is $b$. The composite plate is subjected to the base excitation denoted by $u_{g}(t)$ at its clamping end. Figure 3(b) shows the cross section of composite plate; in the figure, $\delta$ is the distance between the interface of coating-substrate and the neutral surface.

In the linear analytical model, the strain dependent characteristic of hard coating is ignored and the elastic modulus of hard coating can be reexpressed as

$$
E_{c}^{*}=E_{c R}\left(1+i \eta_{c}\right) .
$$

Young's modulus of metal substrate is $E_{s}$, and the material damping of metal substrate has been included in the remaining equivalent viscous damping, so it will not be considered any more.

It is assumed that the base excitation at clamping end of composite plate is harmonic and is expressed as

$$
u_{g}(t)=U_{G} e^{i \omega t},
$$

where $U_{G}$ is the level of base excitation and $\omega$ is the angular frequency.

Hence, the total displacement $d(x, y, t)$ of an arbitrary point on cantilever composite plate can be determined as

$$
d(x, y, t)=u_{g}(t)+w(x, y, t),
$$

where $w(x, y, t)$ refers to the deflection of any point in the hard-coating plate. Obviously, if the deflection is known, 
the total displacement of any point can be obtained. The deflection and natural characteristic of hard-coating plate will be deduced in the following.

The distance $\delta$ between the interface of coating-substrate and neutral surface can be determined as [20]

$$
\delta=\frac{E_{s} H_{s}^{2}-E_{c R} H_{c}^{2}}{2\left(E_{s} H_{s}+E_{c R} H_{c}\right)} .
$$

According to the classic thin plate theory, the strain energy of hard-coating thin plate can be determined as

$$
\begin{aligned}
U & =\frac{1}{2} \iiint_{V}\left(\sigma_{x} \varepsilon_{x}+\sigma_{y} \varepsilon_{y}+\tau_{x y} \gamma_{x y}\right) \mathrm{d} V=\frac{1}{2} \\
& \cdot \iint_{A}\left\{D_{1}\left[\left(\frac{\partial^{2} w}{\partial x^{2}}\right)^{2}+\left(\frac{\partial^{2} w}{\partial y^{2}}\right)^{2}\right]\right. \\
& \left.+2 D_{2} \frac{\partial^{2} w}{\partial x^{2}} \frac{\partial^{2} w}{\partial y^{2}}+D_{3}\left(\frac{\partial^{2} w}{\partial x \partial y}\right)^{2}\right\} \mathrm{d} A,
\end{aligned}
$$

where $V, A$ are the volume and area of composite plate and the variables of $D_{1}, D_{2}$, and $D_{3}$ are shown as follows:

$$
\begin{aligned}
& D_{1}=\frac{E_{s} N_{1}}{1-\mu_{s}^{2}}+\frac{E_{c}^{*} N_{2}}{1-\mu_{c}^{2}}, \\
& D_{2}=\frac{E_{s} N_{1} \mu_{s}}{1-\mu_{s}^{2}}+\frac{E_{c}^{*} N_{2} \mu_{c}}{1-\mu_{c}^{2}}, \\
& D_{3}=4 G_{s} N_{1}+4 G_{c}^{*} N_{2},
\end{aligned}
$$

where $G_{s}$ and $G_{c}^{*}$ are shear modulus of metal substrate and hard coating, respectively, and $\mu_{s}$ and $\mu_{c}$ are Poisson's ratio of metal substrate and hard coating, respectively, where

$$
\begin{aligned}
& N_{1}=\frac{H_{s}^{3}}{12}+H_{s}\left(\frac{H_{s}}{2}-\delta\right)^{2}, \\
& N_{2}=\frac{1}{3} H_{c}^{3}+\delta\left(H_{c}^{2}+\delta H_{c}\right) .
\end{aligned}
$$

It can be seen from (18) and (19) that the material damping of hard coating has been included in the calculation of strain energy of system.

The kinetic energy of hard-coating plate is

$$
T=\frac{1}{2}\left(\rho_{s} H_{s}+\rho_{c} H_{c}\right) \iint_{A}\left(\frac{\partial w}{\partial t}\right)^{2} \mathrm{~d} A .
$$

Besides the above energies, the energy consumption by boundary conditions and fluid in air should also be contained in the composite plate system, and as known, this energy consumption is caused by the remaining equivalent viscous damping and is described as

$$
D=\frac{c}{2} \iint_{A}\left(\frac{\partial w}{\partial t}\right)^{2} \mathrm{~d} A
$$

where $c$ is the equivalent viscous damping coefficient. For the $n$-order, it can be expressed as

$$
c_{n}=\frac{2 \xi_{s, n} \omega_{s, n}}{\left(\rho_{s} H_{s}+\rho_{c} H_{c}\right)},
$$

where $\xi_{s, n}, \omega_{s, n}$ are the damping ratio and natural frequency of the $n$-order of uncoated plate, respectively, and practice has shown that this equivalent cannot produce big analysis error.

According to the two-dimensional beam function method, the deflection of the hard-coating composite plate can be approximately expressed as

$$
w(x, y, t)=\sum_{l=1}^{R} \sum_{p=1}^{N} X_{l}(x) Y_{p}(y) a_{l p}(t),
$$

where $X_{l}(x)$ refers to the $l$-order modal shape function of clamped-free beam, $Y_{p}(y)$ refers to the $p$-order modal shape function of free-free beam, and $R, N$ are the considered orders in the analysis. $a_{l p}(t)$ is the contribution coefficient of the beam function and refers to the $l$-order and the $p$-order. If the plate is excited by a single frequency, it can be assumed that

$$
a_{l p}(t)=a_{l p} e^{i \omega t}
$$

Substituting (24) into (18), (21), and (22), respectively, then the expressions of strain energy, kinetic energy, and the remaining equivalent viscous damping consumption energy of hard-coating plate can be obtained and expressed by the two-dimensional beam function. Set $L=T-U$ and substitute these energy equations into the following Lagrange equations:

$$
\begin{aligned}
\frac{\mathrm{d}}{\mathrm{d} t} \frac{\partial L}{\partial \dot{a}_{l p}(t)}-\frac{\partial L}{\partial a_{l p}(t)}+\frac{\partial D}{\partial \dot{a}_{l p}(t)} & =0, \\
& \left(\begin{array}{l}
l=1,2,3, \ldots, R \\
p=1,2,3, \ldots, N
\end{array}\right) .
\end{aligned}
$$

After rearrangement, the final motion equation of hardcoating plate can be yielded:

$$
\left(\mathbf{K}+i \mathbf{C}-\omega^{2} \mathbf{M}+i \omega B\right) \mathbf{a}=\mathbf{q}
$$

where

$$
\mathbf{a}=\left[\begin{array}{llllllllll}
a_{11} & \cdots & a_{1 p} & a_{21} & \cdots & a_{2 p} & \cdots & a_{l p} & \cdots & a_{R N}
\end{array}\right]^{T}
$$

refers to the response vector, $\mathbf{C}$ is the material damping matrix of hard coating, $\mathbf{B}$ is the remaining equivalent viscous damping of system, and $\mathbf{q}$ is the excitation force vector.

To solve the natural frequencies, the damping matrix and excitation force vector are neglected in (27), and then the characteristic equation is obtained and expressed as

$$
\left(\mathbf{K}-\omega_{n}^{2} \mathbf{M}\right) \mathbf{a}=0 .
$$

Solving the characteristic equation, the natural frequencies $\omega_{n}^{2}$ of hard-coating plate can be obtained.

From (27), the response vector a can be solved corresponding to a specific excitation frequency. Substituting a to (24), the deflection of any point on hard-coating composite plate can be gotten. Finally, the vibration response of any point under base excitation can be obtained referring to (16). 
TABLE 1: The dimensions and material parameters of hard-coating plate.

\begin{tabular}{|c|c|c|c|c|c|c|c|}
\hline Type of materials & Length $(\mathrm{mm})$ & Width $(\mathrm{mm})$ & Thickness (mm) & Storage modulus (GPa) & Density $\left(\mathrm{kg} / \mathrm{m}^{3}\right)$ & Poisson's ratio & Loss factor \\
\hline Substrate Ti-6Al-4V & 133.1 & 109.6 & 1.44 & 110.32 & 4420 & 0.3 & 0.0007 \\
\hline $\begin{array}{l}\text { Hard coating } \\
\text { NiCoCrAlY + YSZ }\end{array}$ & 133.1 & 109.6 & 0.3 & 54.494 & 5600 & 0.3 & 0.0212 \\
\hline
\end{tabular}

TABLE 2: Natural frequencies of hard-coating cantilever plate $(\mathrm{Hz})$.

\begin{tabular}{lcccccc}
\hline Order & 1 & 2 & 3 & 4 & 5 & \multicolumn{1}{c}{6} \\
\hline Analytical calculation $f^{A}$ & 71.95 & 204.29 & 445.92 & 715.15 & 776.72 & 1263.13 \\
FE calculation $f^{F}$ & 72.68 & 204.86 & 449.73 & 716.19 & 771.15 & 1271.80 \\
$\left|f^{A}-f^{F}\right| / f^{F}$ & $1.00 \%$ & $0.28 \%$ & $0.85 \%$ & $0.15 \%$ & $0.72 \%$ & $0.68 \%$ \\
\hline
\end{tabular}

TABLE 3: The resonant displacement responses obtained by analyti$\mathrm{cal}$ and finite element $\mathrm{method} / \mu \mathrm{m}$.

\begin{tabular}{lcccc}
\hline Order & 1 & 3 & 5 & 6 \\
\hline Analytical calculation $d^{A}$ & 824.66 & 55.65 & 1.32 & 6.30 \\
FE calculation $d^{F}$ & 865.39 & 58.46 & 1.29 & 6.45 \\
$\left|d^{A}-d^{F}\right| / d^{F}$ & $4.71 \%$ & $4.81 \%$ & $2.33 \%$ & $2.32 \%$ \\
\hline
\end{tabular}

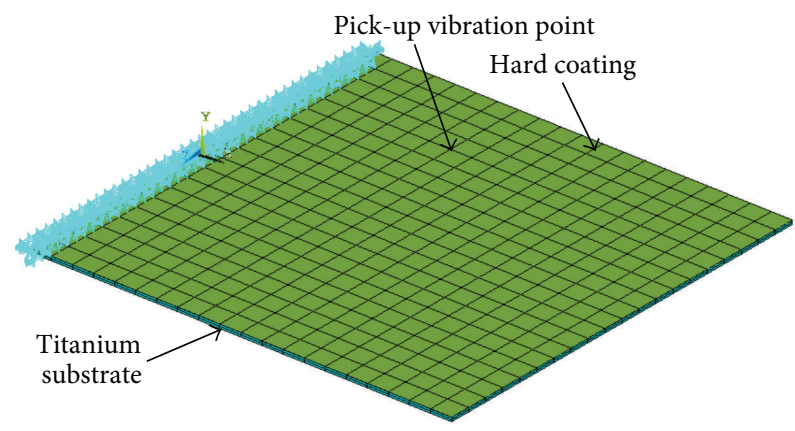

FIGURE 4: FE model of hard-coating plate.

3.2. Rationality Verification of the Developed Model. To verify the rationality of developed model, here, the experiment object in Section 4 was taken, and the natural frequencies and harmonic response were solved by the developed model and commercial finite element software ANSYS, respectively. The mentioned experiment object in this study is the cantilever titanium cantilever plate coated with NiCoCrAlY + YSZ hard coating on one side, and the relative dimensions and material parameters are listed in Table 1 . It should be noted that the storage modulus and density of hard coating in the table were obtained by the experiment shown in Section 4. Because of belonging to linear calculation, only the mechanical parameters of hard coating corresponding to a certain response amplitude were introduced into these calculation models. The excitation level was set as $1 \mathrm{~g}$ and the modal damping ratios needed in this calculation are also shown in Section 4. Referring to the coordinate in Figure 3, the pick-up vibration point is $x=80.6 \mathrm{~mm}, y=41 \mathrm{~mm}$. The finite element model of hard-coating plate created by ANSYS software is shown in Figure 4, SHELL281 element is adopted to simulate both the

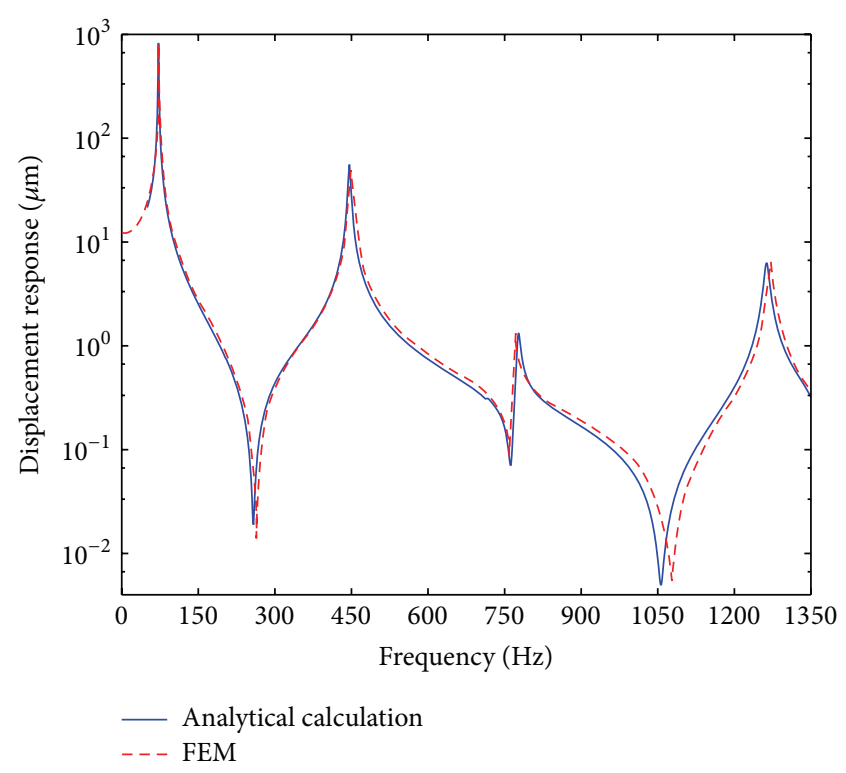

FIGURE 5: The harmonic responses of pick-up vibration point on the hard-coating plate.

substrate and hard coating, and there are 800 elements and 2562 nodes in total.

The natural frequencies obtained by analytical and finite element method are listed in Table 2, the harmonic response at a range of $0-1350 \mathrm{~Hz}$ is shown in Figure 5, and the resonant responses extracted by the peak value of harmonic responses are listed in Table 3.

It can be seen from Figure 5 that the 2nd and 4th order resonant responses have not been excited effectively for both analytical and FE calculations. The reason is that these orders are torsion modes, while applying the uniform excitation in this analysis cannot excite these modal shapes effectively. Therefore, these orders cannot be used to identify the loss factor of hard coating, because the resonant response needs to be obtained during the identification of loss factor.

As can be seen in Tables 2 and 3, there are little differences in the first 6 orders of natural frequencies and resonant displacement responses between analytical calculation and finite element method. Among them, the difference of natural 
frequency is less than $1 \%$ and the difference of resonant response is less than 5\%; then the rationality of analytical model is verified. Compared with the finite element method, the analytical calculation has higher computational efficiency and the program code is easily packaged into a special software, so in this study, the analytical calculation was adopted to identify the mechanical parameters of hard coating for the hard-coating plate.

3.3. Determination Method of Reference Strain. To characterize the hard-coating parameters with strain dependent characteristic accurately, the reference strain needs to be derived. Usually, the maximum strain along the interface between the coating and the substrate is usually used as the reference strain $[7,14]$. For the hard-coating cantilever plate in this study, according to classic thin plate theory, there are three independent strains, such as the normal strain $\varepsilon_{x}, \varepsilon_{y}$ of $x, y$ direction and the shear strain $\gamma_{x y}$ in $x y$ plane. It is irrational to arbitrarily choose one of these strains as the reference strain, and for this reason, the equivalent strain was adopted as reference strain to describe the strain dependent characteristic of hard coating in this study. The following is the solving process of the reference strain for the hard-coating thin plate.

According to classical plate theory, the strain of any point in the hard-coating plate can be expressed as

$$
\begin{gathered}
\varepsilon_{x}=-z \frac{\partial^{2} w}{\partial x^{2}}, \\
\varepsilon_{y}=-z \frac{\partial^{2} w}{\partial y^{2}}, \\
\gamma_{x y}=-2 z \frac{\partial^{2} w}{\partial x \partial y},
\end{gathered}
$$

where $z$ is the distance between the interface of coatingsubstrate and neutral surface.

Furthermore, from physical equation, the stress of an arbitrary point can be described as

$$
\begin{aligned}
\sigma_{x} & =\frac{E_{e}}{1-\mu_{e}^{2}}\left(\varepsilon_{x}+\mu_{e} \varepsilon_{y}\right) \\
& =-\frac{E_{e}}{1-\mu_{e}^{2}} z\left(\frac{\partial^{2} w}{\partial x^{2}}+\mu_{e} \frac{\partial^{2} w}{\partial y^{2}}\right),
\end{aligned}
$$

$$
\begin{aligned}
\sigma_{y} & =\frac{E_{e}}{1-\mu_{e}^{2}}\left(\varepsilon_{y}+\mu_{e} \varepsilon_{x}\right) \\
& =-\frac{E_{e}}{1-\mu_{e}^{2}} z\left(\frac{\partial^{2} w}{\partial y^{2}}+\mu_{e} \frac{\partial^{2} w}{\partial x^{2}}\right), \\
\tau_{x y} & =G_{e} \gamma_{x y}=-2 G_{e} z \frac{\partial^{2} w}{\partial x \partial y},
\end{aligned}
$$

where $\sigma_{x}, \sigma_{y}$ are the normal stress of $x, y$ direction, respectively, $\tau_{x y}$ is the shear stress in $x y$ plane, and $E_{e}, \mu_{e}$, and $G_{e}$ are the equivalent storage modulus, equivalent Poisson's ratio, and equivalent shear modulus of hard-coating composite plate, respectively.

Here, the equivalent strain of hard-coating plate was determined according to the principle of equal strain energy density, and the relative expression is

$$
\sigma_{x} \varepsilon_{x}+\sigma_{y} \varepsilon_{y}+\tau_{x y} \gamma_{x y}=\sigma_{e} \varepsilon_{e}
$$

where $\sigma_{e}$ is the equivalent stress and

$$
\sigma_{e}=E_{e} \varepsilon_{e} .
$$

Substituting (30) and ((31a), (31b), and (31c)) and (33) to (32) yields

$$
\begin{aligned}
& \frac{E_{e} z^{2}}{1-\mu_{e}^{2}}\left[\left(\frac{\partial^{2} w}{\partial x^{2}}\right)^{2}+2 \mu_{e}\left(\frac{\partial^{2} w}{\partial x^{2}}\right)\left(\frac{\partial^{2} w}{\partial y^{2}}\right)+\left(\frac{\partial^{2} w}{\partial y^{2}}\right)^{2}\right. \\
& \left.\quad+2\left(1-\mu_{e}\right)\left(\frac{\partial^{2} w}{\partial x \partial y}\right)^{2}\right]=E_{e} \varepsilon_{e}^{2}
\end{aligned}
$$

Then the solving formula of equivalent strain can be obtained:

$$
\begin{aligned}
\varepsilon_{e}^{2} & =\frac{z^{2}}{1-\mu_{e}^{2}}\left[\left(\frac{\partial^{2} w}{\partial x^{2}}\right)^{2}+2 \mu_{e}\left(\frac{\partial^{2} w}{\partial x^{2}}\right)\left(\frac{\partial^{2} w}{\partial y^{2}}\right)\right. \\
& \left.+\left(\frac{\partial^{2} w}{\partial y^{2}}\right)^{2}+2\left(1-\mu_{e}\right)\left(\frac{\partial^{2} w}{\partial x \partial y}\right)^{2}\right] .
\end{aligned}
$$

Because the expression of complex response is introduced during the analytical derivation, the deflection $w(x, y, t)$ of hard-coating plate is also a complex, while the equivalent strain should be a real, so the final solving formula of equivalent strain is

$$
\varepsilon_{e}=\sqrt{\frac{z^{2}}{1-\mu_{e}^{2}}\left|\left(\frac{\partial^{2} w}{\partial x^{2}}\right)^{2}+2 \mu_{e}\left(\frac{\partial^{2} w}{\partial x^{2}}\right)\left(\frac{\partial^{2} w}{\partial y^{2}}\right)+\left(\frac{\partial^{2} w}{\partial y^{2}}\right)^{2}+2\left(1-\mu_{e}\right)\left(\frac{\partial^{2} w}{\partial x \partial y}\right)^{2}\right|},
$$

where $|\cdot|$ represents the solution of modulus of complex.

It can be known from Figure 3(b) that the $z$ coordinate value in interface is the distance $\delta$. Furthermore, from the strain response distribution of hard-coating plateunder resonant status, the location of maximum strain can be found. Substituting $\delta$ and the coordinate value of the location of maximum strain into (36), the reference strain used to characterize the strain dependent characteristic of hard coating can be obtained. 


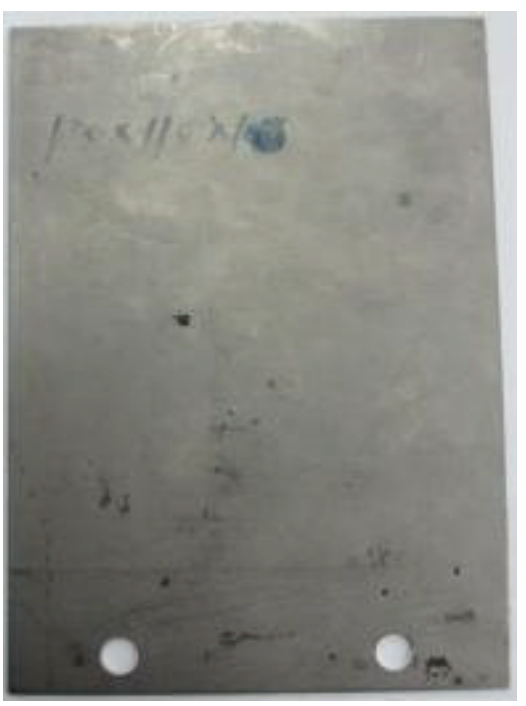

(a) Uncoated plate

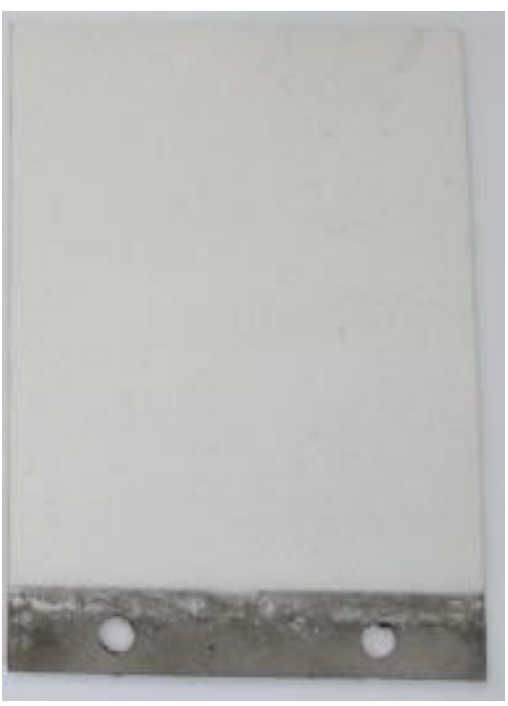

(b) Coated plate

FIGURE 6: The experiment specimens.

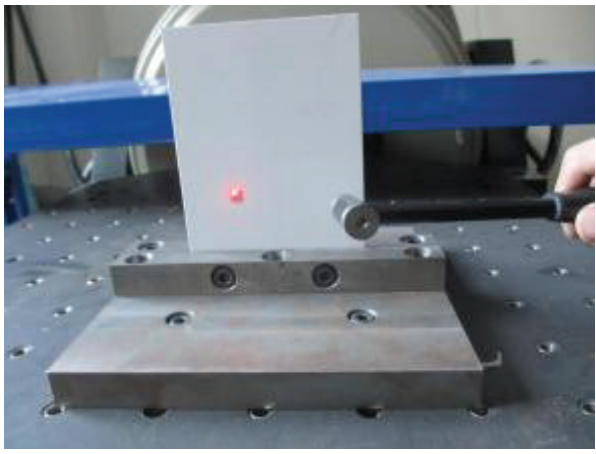

(a) Hammering test

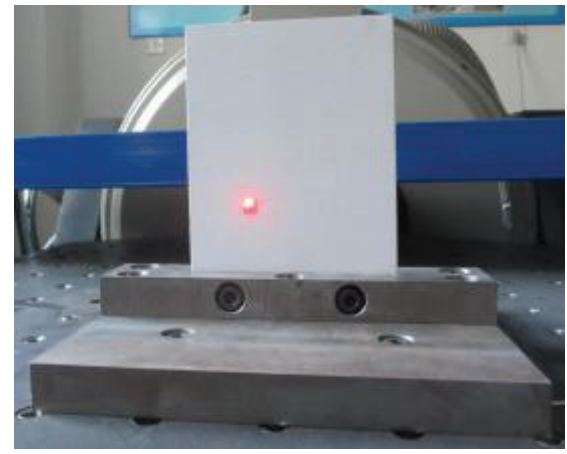

(b) Vibration shaker test

Figure 7: Vibration test scenes of cantilever hard-coating plate.

\section{Vibration Experiments of Hard-Coating Plate}

In this section, referring to the procedure of identifying storage modulus and loss factor based on inverse method shown in Figures 1 and 2, the vibration experiments of hard-coating plate were performed under different excitation levels.

4.1. Experiment Specimens and Test System. Here, the titanium plate coated with NiCoCrAlY + YSZ hard coating on one side (shown in Figure 6) was taken as experiment specimen to demonstrate the identification of equivalent storage modulus and loss factor of the mixing coating. The preparation technology of hard coating in this experiment is APS; here, NiCoCrAlY is bonding coating and YSZ is damping coating. The relative dimensions and material parameters of the hard-coating plate have been listed in Table 1. It should be noted that the length of plate in Table 1 is the effective length participating in dynamic analysis, while the whole length of plate is $153.1 \mathrm{~mm}$. So the length of clamping area providing the cantilever constraint status of hard-coating plate is $20 \mathrm{~mm}$. All the geometry dimensions were obtained by vernier caliper, and the mechanical parameters of titanium substrate were known. The density of hard coating was obtained by the following formula:

$$
\rho_{c}=\frac{m-m_{s}}{a b H_{c}},
$$

where $m$ is the mass of hard-coating plate and $m_{s}$ is the mass of titanium plate. These masses need to be measured and the measuring device is AR1140 electronic balance. The storage modulus and loss factor of NiCoCrAlY + YSZ hard coating were identified by the proposed inverse method in this study.

Titanium plate was fixed on the vibration shaker in cantilever status, and the tightening torque of blot was $34 \mathrm{~N} \cdot \mathrm{m}$. According to the need of inverse method, the hammering test and vibration shaker test were performed and the relative testing scenes are shown in Figure 7, respectively. Here, 
TABLE 4: The instruments used in this test.

\begin{tabular}{lc}
\hline Number & Name \\
\hline 1 & KINGDESIGN EM-1000F vibration shaker \\
2 & LMS SCADAS mobile front-end \\
3 & PCB 8206-001 54627 modal hammer \\
4 & Polytec PDV-100 laser vibrometer \\
5 & LMS.Testlab workstation \\
\hline
\end{tabular}

hammering test was used to obtain the natural frequencies of uncoated and coated plate, while vibration shaker test included sweeping test and fixed frequency excitation test, which were used to obtain the resonant frequency, resonant response, and modal loss factor of uncoated and coated plate. All the needed test instruments are listed in Table 4.

4.2. Test Process and Results. Here, only the 6th order mode of uncoated and coated cantilever plate was chosen as an example to demonstrate the process of identifying the mechanical parameters of NiCoCrAlY + YSZ hard coating based on the proposed inverse method. Besides the 6th order, the 3rd or 5 th order can also be chosen in the considered frequency range. However, the 2 nd and 4 th modes are not suitable to identify loss factor of hard coating, because they are torsion mode. The 1st mode is affected by boundary condition of clamping area severely, so it is also not suitable. The required test data include the natural frequencies and modal damping ratios of the first 6 orders of uncoated and coated plate and the resonant frequencies, resonant responses, and modal damping ratios of the 6th order of uncoated and coated plate under different excitation levels. In this experiment, for the vibration shaker test, the selected excitation levels were $1 \mathrm{~g}, 2 \mathrm{~g}, 4 \mathrm{~g}$, and $6 \mathrm{~g}$, respectively. Vibration responses were picked up by laser vibrometer for all the tests and the pickup vibration point was consistent with the dynamic analysis in Section 3.2.

The modal hammer was used to tap the uncoated and coated cantilever plate and the relative frequency response functions (FRF) within the considered frequency range can be obtained. Furthermore, natural frequencies were gotten by picking up the frequencies corresponding to peak amplitudes of FRF and modal damping ratios were confirmed by using half power bandwidth method. The obtained first 6 orders natural frequencies and modal damping ratios of uncoated and coated cantilever plate are listed in Table 5.

Referring to the 6 th order natural frequency of cantilever thin plate obtained by hammering method, the sweeping range can be set, and then the sweeping tests were conducted under different excitation levels. Figure 8 is the $3 \mathrm{D}$ waterfall figure of coated plate under $1 \mathrm{~g}$ excitation level obtained by the sweeping test. Similarly, the 3D waterfall figures of uncoated and coated plate under other excitation levels can also be gotten. Furthermore, these 3D waterfall figures were projected onto the frequency domain, and then the frequency responses of uncoated and coated plate around the 6th order can be obtained. Figure 9 is the frequency response of coated plate under $1 \mathrm{~g}$ excitation level, which is corresponding

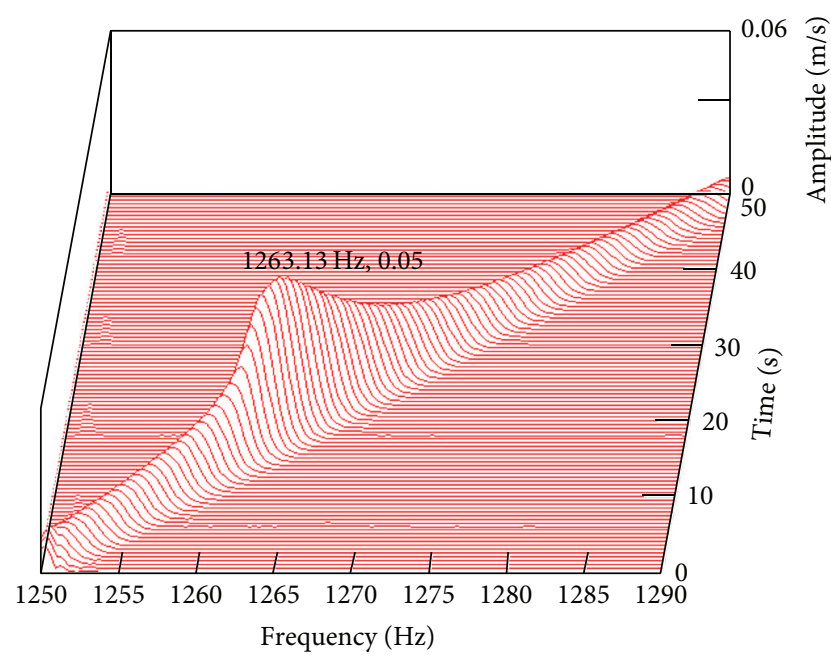

FIGURE 8: The 3D waterfall figure of coated plate around the 6th order under $1 \mathrm{~g}$ excitation level.

to Figure 8. The resonant frequencies and modal damping ratios under different excitation levels can be identified from these frequency responses for the uncoated and coated plate. It should be noted that, here, modal damping ratios were extracted by the frequency domain bandwidth method [21]. The resonant response is obtained by fixed resonant frequency excitation, and Figure 10 is the 6 th order resonant response of coated plate under $1 \mathrm{~g}$ excitation level. The direct result obtained by laser vibrometer is velocity response; to get the displacement response, the following transformation needs to be performed:

$$
d=\frac{v}{\omega}
$$

where $v$ is the measured velocity signal. The resonant frequencies, resonant responses, and modal damping ratios of the 6 th order uncoated and coated plate under different excitation levels are listed in Table 6.

\section{Identification of the Mechanical Parameters of Hard Coating with Strain Dependent Characteristic}

5.1. Identification of Storage Modulus. According to the identification procedure in Figure 1, to obtain the initial value of storage modulus, the first match calculation was performed. The match objects for the first match calculation are the measured multiple orders natural frequencies and the relative orders natural frequencies obtained by calculation for the coated plate. The natural frequencies obtained by test are listed in Table 5 . Here, the 4 th and 6 th orders were chosen to create the objective function of the first match calculation. Of course, other combinations, such as the 3rd and 6 th orders and the 5th and 6th orders, can be also considered. During the first match calculation, the process of determining initial value of storage modulus is listed 
TABLE 5: The first 6 orders natural frequencies and modal damping ratios of uncoated and coated plate obtained by hammering method.

\begin{tabular}{llcccccc}
\hline & Order & 1 & 2 & 3 & 4 & 5 & 6 \\
\hline \multirow{2}{*}{ Uncoated plate } & Natural frequency (Hz) & 73.62 & 189.51 & 441.03 & 715.13 & 754.21 & 1297.88 \\
& Modal damping ratio (\%) & 0.37 & 0.19 & 0.22 & 0.29 & 0.15 & 0.11 \\
\hline \multirow{2}{*}{ Coated plate } & Natural frequency (Hz) & 71.05 & 190.05 & 432.12 & 708.13 & 768.44 & 1263.13 \\
& Modal damping ratio (\%) & 0.57 & 0.24 & 0.24 & 0.43 & 0.45 & 0.25 \\
\hline
\end{tabular}

TABLE 6: The 6th order resonant frequencies, resonant responses, and modal damping ratios of uncoated and coated plate under different excitation levels.

\begin{tabular}{|c|c|c|c|c|c|}
\hline \multicolumn{2}{|c|}{ Excitation level (g) } & 1 & 2 & 4 & 6 \\
\hline \multirow{3}{*}{ Uncoated plate } & Resonant frequency $(\mathrm{Hz})$ & 1297.08 & 1297.00 & 1297.00 & 1297.05 \\
\hline & Resonant response $(\mu \mathrm{m})$ & 13.5 & 31.4 & 68.1 & 96.3 \\
\hline & Modal damping ratio (\%) & 0.11 & 0.11 & 0.11 & 0.11 \\
\hline \multirow{3}{*}{ Coated plate } & Resonant frequency $(\mathrm{Hz})$ & 1263.13 & 1261.88 & 1259.13 & 1258.13 \\
\hline & Resonant response $(\mu \mathrm{m})$ & 6.3 & 12.0 & 22.8 & 33.1 \\
\hline & Modal damping ratio (\%) & 0.25 & 0.26 & 0.27 & 0.28 \\
\hline
\end{tabular}

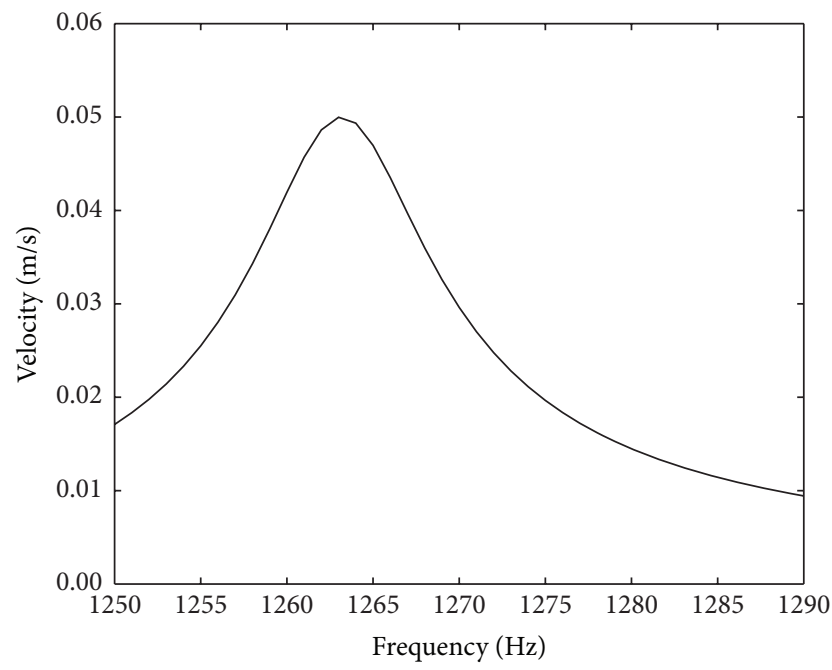

FIGURE 9: Frequency response of coated plate around the 6th order under $1 \mathrm{~g}$ excitation level.

in Table 7. Corresponding to each iteration, the comparisons between calculation and experiment values of the 4 th and 6th orders natural frequencies are listed in Table 8. Finally, the identified initial value of storage modulus is $54.091 \mathrm{GPa}$.

After the initial value has been confirmed, the second match calculation was performed to identify the storage modulus corresponding to different excitation levels. Here, the 6th order measured resonant frequencies under different excitation levels and the relative calculation values for the coated plate were chosen to create the objective function. For the second match calculation, the process of identifying the final storage modulus under different excitation levels is listed in Table 9. Correspondingly, the comparisons between

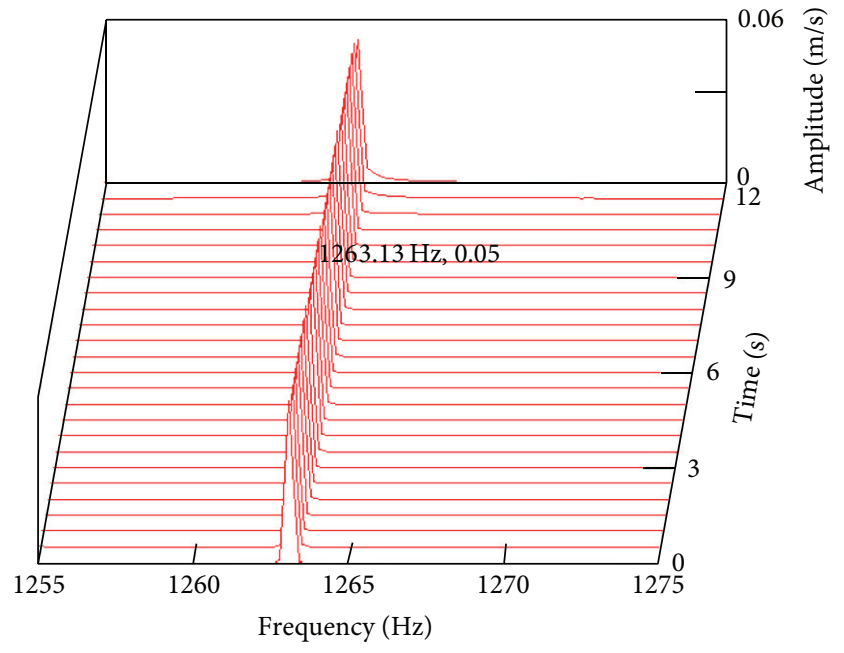

FIGURE 10: The 6th order resonant response of coated plate under $1 \mathrm{~g}$ excitation level.

TABLE 7: The process of identifying initial value of storage modulus.

\begin{tabular}{lccc}
\hline Iteration time & 0 & 1 & 2 \\
\hline Storage modulus $(\mathrm{GPa})$ & 40 & 50.142 & 54.091 \\
\hline
\end{tabular}

calculation and experiment values of the 6th order resonant frequencies under different excitation levels for each iteration are listed in Table 10.

5.2. Identification of the Loss Factor. According to the identification procedure shown in Figure 2, the loss factor of hard coating under different excitation levels was extracted. Substituting the thickness and density of coating and substrate 
TABLE 8: The comparisons between calculation and experiment values of the 4th and 6th orders natural frequencies for each iteration/Hz.

\begin{tabular}{lcccccc}
\hline \multirow{2}{*}{ Iteration time } & \multicolumn{3}{c}{ The 4th order } & \multicolumn{2}{c}{ The 6th order } \\
& Experiment $f_{4}^{E}$ & Calculation $f_{4}^{A}$ & Difference $\left|f_{4}^{A}-f_{4}^{E}\right| / f_{4}^{E}$ & Experiment $f_{6}^{E}$ & Calculation $f_{6}^{A}$ & Difference $\left|f_{6}^{A}-f_{6}^{E}\right| / f_{6}^{E}$ \\
\hline 0 & 708.13 & 688.79 & $2.82 \%$ & 1263.13 & 1216.62 & $3.72 \%$ \\
1 & 708.13 & 707.22 & $0.13 \%$ & 1263.13 & 1249.16 & $1.11 \%$ \\
2 & 708.13 & 714.45 & $0.89 \%$ & 1263.13 & 1261.92 & $0.10 \%$ \\
\hline
\end{tabular}

TABLE 9: The process of identifying the final storage modulus under different excitation levels/GPa.

\begin{tabular}{lcccc}
\hline \multirow{2}{*}{ Iteration time } & \multicolumn{4}{c}{ Excitation level } \\
& $1 \mathrm{~g}$ & $2 \mathrm{~g}$ & $4 \mathrm{~g}$ & $6 \mathrm{~g}$ \\
\hline 0 & 54.091 & 54.091 & 54.091 & 54.091 \\
1 & 54.493 & 54.088 & 53.196 & 52.873 \\
2 & 54.494 & - & 53.198 & 52.876 \\
\hline
\end{tabular}

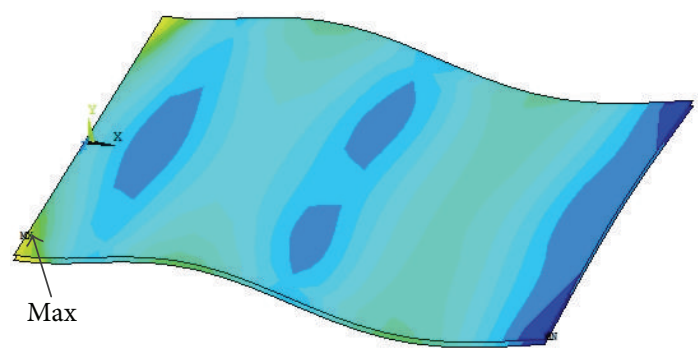

FIGURE 11: Strain distribution corresponding to the 6th order modal shape of composite plate.

listed in Table 1 and the natural frequencies and damping parameters listed in Table 5 to (10), the initial value of loss factor was solved and the value is 0.0192 . According to Table 6, the 6th order resonant responses of coated plate under different excitation levels and the relative calculation values were chosen to create the objective function. For this match calculation, the process of identifying the loss factor of hard coating under different excitation levels is listed in Table 11, and the comparisons between calculation and experiment values of the 6th order resonant responses under different excitation levels for each iteration are listed in Table 12.

\subsection{Characterizing the Mechanical Parameters of Hard Coat-} ing with Strain Dependent Characteristic. To effectively characterize the mechanical parameters of hard coating with strain dependent characteristics, the maximum strain of the composite plate under each excitation level is also needed to be obtained as reference strain. The location of maximum strain can be found through the modal shape of hard-coating plate, and Figure 11 is the strain distribution corresponding to the 6th order modal shape of composite plate obtained by ANSYS software. According to the coordinate system in ANSYS, it can be seen that the maximum strain locates at $x=0, z=49.32 \mathrm{~mm}$. If the coordinate of analytical model in Figure 3 is chosen as reference coordinate, the location of maximum strain is $x=0, y=5.48 \mathrm{~mm}$. For each excitation level, based on the premise of determining the deflection distribution $w(x, y)$ of hard-coating plate, substituting the obtained coordinate value and $z$ coordinate value $\delta$ into (36), the maximum strain which is a reference strain can be solved. The final reference strains corresponding to the 6th order resonance of composite plate under different excitation levels are listed in Table 13.

With the reference strain as horizontal axis and the storage modulus or loss factor obtained by inverse method as vertical axis, the relation curves can be drawn and then the mechanical parameters of hard coating are characterized according to the strain dependent characteristic. The obtained relation curves are shown in Figure 12.

By comparison, it can be found that the change rules of storage modulus and loss factor of hard coating with the reference strain are almost consistent with the results listed in the other similar references [7-9]. While the experiment object in this study was hard-coating cantilever thin plate, that of others was all beam-shape specimens. If we consider that the mechanical parameters of hard coating are affected by preparation technology significantly, the identification results herein will be more suitable to create the model of plate-shape structure coated with hard coating. Very unfortunately, due to the limitation of laser vibrometer range, the data points were not enough in the current study; however, it does not affect the rationality of the developed method.

In addition, these discrete point values of hard-coating parameters can be fitted by polynomial, for example,

$$
E_{c}^{*}=E_{c 0}^{*}+E_{c 1}^{*} \varepsilon_{e}+E_{c 2}^{*} \varepsilon_{e}^{2}+E_{c 3}^{*} \varepsilon_{e}^{3}+\ldots
$$

where $E_{c 0}^{*}, E_{c 1}^{*}, E_{c 2}^{*}, E_{c 3}^{*}, \ldots$ are fitting parameters. If we substitute the polynomial expression to an analysis model, then the goal of including these strain dependent mechanical parameters of hard coating into a nonlinear dynamic model of composite structure can be achieved.

\section{Conclusions}

A hard-coating cantilever thin plate under base excitation was taken as the research object, and an inverse method was developed to identify hard-coating mechanical parameters with strain dependent characteristic. Some important conclusions are listed as follows.

(1) The storage modulus of hard coating directly impacts the natural frequency of hard-coating composite plate, while the loss factor has obvious influence on 
TABLE 10: The comparisons between calculation and experiment values of the 6th order resonant frequencies under different excitation levels for each iteration/Hz.

\begin{tabular}{lccccc}
\hline & Excitation level & $1 \mathrm{~g}$ & $2 \mathrm{~g}$ & $4 \mathrm{~g}$ & $6 \mathrm{~g}$ \\
\hline Iteration time & Experiment $f_{6}^{E}$ & 1263.13 & 1261.88 & 1259.13 & 1258.13 \\
\hline \multirow{2}{*}{0} & Calculation $f_{6}^{A, 0}$ & 1261.92 & 1261.92 & 1261.92 & $0.16 \%$ \\
& Difference $\left|f_{6}^{A, 0}-f_{6}^{E}\right| / f_{6}^{E}$ & $0.10 \%$ & $0.002 \%$ & 1261.92 \\
\multirow{2}{*}{1} & Experiment $f_{6}^{A, 1}$ & 1263.10 & 1261.885 & $0.31 \%$ \\
\hline \multirow{2}{*}{2} & Difference $\left|f_{6}^{A, 1}-f_{6}^{E}\right| / f_{6}^{E}$ & $0.0024 \%$ & $0.0004 \%$ & $0.0024 \%$ & 1258.10 \\
& Calculation $f_{6}^{A, 2}$ & 1263.132 & - & 1259.133 & $0.004 \%$ \\
\hline
\end{tabular}

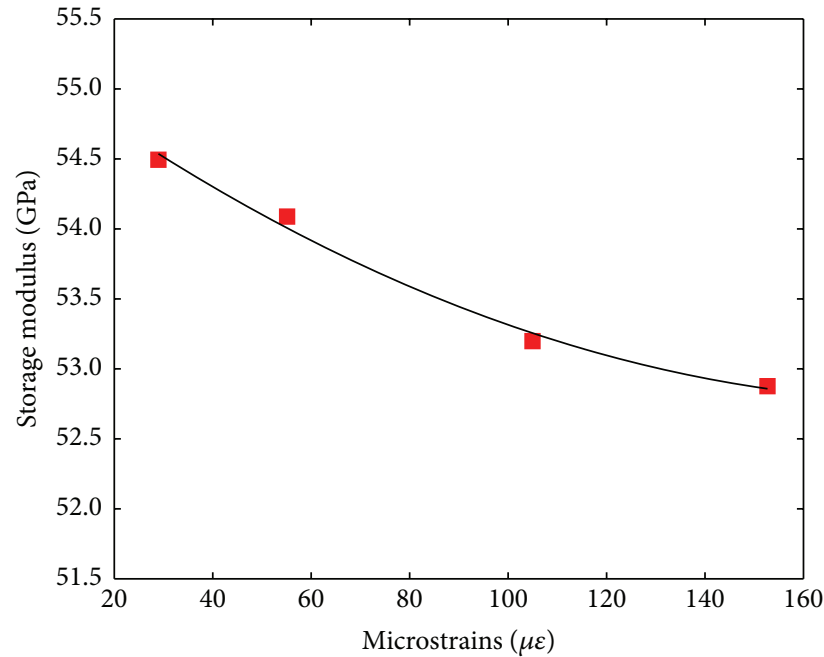

(a) The storage modulus

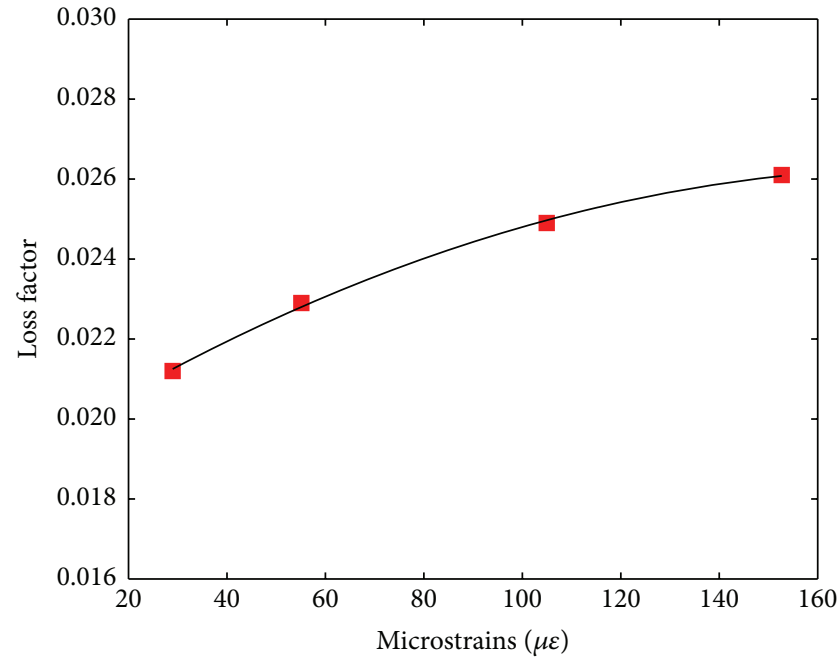

(b) The loss factor

FIGURE 12: Characterization of hard-coating mechanical parameters with strain dependent characteristic.

TABLE 11: The process of identifying loss factor of hard coating under different excitation levels.

\begin{tabular}{lcccc}
\hline Excitation level & $1 \mathrm{~g}$ & $2 \mathrm{~g}$ & $4 \mathrm{~g}$ & $6 \mathrm{~g}$ \\
\hline 0 & 0.0192 & 0.0192 & 0.0192 & 0.0192 \\
1 & 0.0210 & 0.0224 & 0.0239 & 0.0247 \\
2 & 0.0212 & 0.0228 & 0.0248 & 0.0261 \\
3 & 0.0212 & 0.0229 & 0.0249 & - \\
\hline
\end{tabular}

the resonant response. So the storage modulus and loss factor of hard coating can be effectively identified by matching calculation of inverse method.

(2) When performing the identification of mechanical parameters of hard coating using the inverse method, a large amount of calculation is usually needed for the match calculation. But choosing the initial value reasonably can effectively reduce the strength of calculation. In the presented procedures of inverse method, the methods of determining initial values of both storage modulus and loss factor are given, which can save the calculation time greatly. In this study, during the identification of storage modulus and loss factor of NiCoCrAlY + YSZ hard coating, only two and three times of iteration calculation were performed before the convergent was achieved.

(3) By comparison, it can be found that the change rules of storage modulus and loss factor of hard coating with the reference strain in this study are almost consistent with the results listed in the other similar references, while the experiment object in this study was hard-coating cantilever thin plate but that of others was all beam-shape specimens. If we consider that the mechanical parameters of hard coating are affected by preparation technology significantly, the identification results herein will be more suitable to create the model of plate-shape structure coated with hard coating.

\section{Conflict of Interests}

The authors declare that there is no conflict of interests regarding the publication of this paper. 
TABLE 12: The comparisons between calculation and experiment values of the 6th order resonant responses under different excitation levels for each iteration $/ \mu \mathrm{m}$.

\begin{tabular}{|c|c|c|c|c|c|}
\hline \multicolumn{2}{|c|}{ Excitation level } & \multirow{2}{*}{$\frac{1 \mathrm{~g}}{6.3}$} & \multirow{2}{*}{$\begin{array}{c}2 \mathrm{~g} \\
12.0\end{array}$} & \multirow{2}{*}{$\begin{array}{c}4 \mathrm{~g} \\
22.8\end{array}$} & \multirow{2}{*}{$\frac{6 \mathrm{~g}}{33.1}$} \\
\hline Iteration time & Experiment $d_{6}^{E}$ & & & & \\
\hline \multirow{2}{*}{0} & Calculation $d_{6}^{A, 0}$ & 6.763 & 13.592 & 27.478 & 41.380 \\
\hline & Difference $\left|d_{6}^{A, 0}-d_{6}^{E}\right| / d_{6}^{E}$ & $7.35 \%$ & $12.26 \%$ & $20.52 \%$ & $25.01 \%$ \\
\hline \multirow{2}{*}{1} & Calculation $d_{6}^{A, 1}$ & 6.331 & 12.167 & 23.481 & 34.482 \\
\hline & Difference $\left|d_{6}^{A, 1}-d_{6}^{E}\right| / d_{6}^{E}$ & $0.49 \%$ & $1.39 \%$ & $2.99 \%$ & $4.17 \%$ \\
\hline \multirow{2}{*}{2} & Calculation $d_{6}^{A, 1}$ & 6.3004 & 12.007 & 22.808 & 33.103 \\
\hline & Difference $\left|d_{6}^{A, 1}-d_{6}^{E}\right| / d_{6}^{E}$ & $0.063 \%$ & $0.058 \%$ & $0.035 \%$ & $0.009 \%$ \\
\hline \multirow{2}{*}{3} & Calculation $d_{6}^{A, 2}$ & 6.3001 & 12.001 & 22.802 & - \\
\hline & Difference $\left|d_{6}^{A, 2}-d_{6}^{E}\right| / d_{6}^{E}$ & $0.006 \%$ & $0.008 \%$ & $0.009 \%$ & - \\
\hline
\end{tabular}

TABLE 13: Reference strains corresponding to the 6th order resonance of composite plate under different excitation levels/ $\mu \varepsilon$.

\begin{tabular}{lcccc}
\hline Excitation level & $1 \mathrm{~g}$ & $2 \mathrm{~g}$ & $4 \mathrm{~g}$ & $6 \mathrm{~g}$ \\
\hline Strain & 28.98 & 55.11 & 104.96 & 152.70 \\
\hline
\end{tabular}

\section{Acknowledgments}

This project was supported by the National Natural Science Foundation of China (Grant no. 51375079) and the Fundamental Research Funds for the Central Universities of China (Grant no. N140301001). In addition, the first author (Wei Sun) would like to thank the University of Akron for providing a visiting professor position to carry out this research work.

\section{References}

[1] A. M. Limarga, T. L. Duong, G. Gregori, and D. R. Clarke, "High-temperature vibration damping of thermal barrier coating materials," Surface and Coatings Technology, vol. 202, no. 47, pp. 693-697, 2007.

[2] W. Grzesik, Z. Zalisz, and P. Nieslony, "Friction and wear testing of multilayer coatings on carbide substrates for dry machining applications," Surface and Coatings Technology, vol. 155, no. 1, pp. 37-45, 2002.

[3] S. Hassani, M. Bielawski, W. Beres, L. Martinu, M. Balazinski, and J. E. Klemberg-Sapieha, "Predictive tools for the design of erosion resistant coatings," Surface and Coatings Technology, vol. 203, no. 3-4, pp. 204-210, 2008.

[4] C. Blackwell, A. Palazotto, T. J. George, and C. J. Cross, “The evaluation of the damping characteristics of a hard coating on titanium," Shock and Vibration, vol. 14, no. 1, pp. 37-51, 2007.

[5] F. Ivancic and A. Palazotto, "Experimental considerations for determining the damping coefficients of hard coatings," Journal of Aerospace Engineering, vol. 18, no. 1, pp. 8-17, 2005.

[6] G. Y. Du, D. C. Ba, Z. Tan, W. Sun, K. Liu, and Q. K. Han, "Vibration damping performance of ZrTiN coating deposited by arc ion plating on TC4 Titanium alloy," Surface and Coatings Technology, vol. 229, pp. 172-175, 2013.

[7] P. J. Torvik, "Determination of mechanical properties of nonlinear coatings from measurements with coated beams," International Journal of Solids and Structures, vol. 46, no. 5, pp. 10661077, 2009.
[8] S. A. Reed, A. N. Palazotto, and W. P. Baker, "An experimental technique for the evaluation of strain dependent material properties of hard coatings," Shock and Vibration, vol. 15, no. 6, pp. 697-712, 2008.

[9] N. Tassini, K. Lambrinou, I. Mircea, M. Bartsch, S. Patsias, and O. Van der Biest, "Study of the amplitude-dependent mechanical behaviour of yttria-stabilised zirconia thermal barrier coatings," Journal of the European Ceramic Society, vol. 27, no. 2-3, pp. 1487-1491, 2007.

[10] S. Patsias, N. Tassini, and K. Lambrinou, "Ceramic coatings: effect of deposition method on damping and modulus of elasticity for yttria-stabilized zirconia," Materials Science and Engineering A, vol. 442, no. 1-2, pp. 504-508, 2006.

[11] P.-J. Wei and J.-F. Lin, "A new method developed to evaluate both the hardness and elastic modulus of a coating-substrate system," Surface \& Coatings Technology, vol. 200, no. 7, pp. 24892496, 2005.

[12] H.-J. Kim and Y.-G. Kweon, "Elastic modulus of plasma-sprayed coatings determined by indentation and bend tests," Thin Solid Films, vol. 342, no. 1, pp. 201-206, 1999.

[13] ASTM International, ASTME756-04 Standard Test Method for Measuring Vibration-Damping Properties of Materials, 2005.

[14] S. Patsias, C. Saxton, and M. Shipton, "Hard damping coatings: an experimental procedure for extraction of damping characteristics and modulus of elasticity," Materials Science and Engineering A, vol. 370, no. 1-2, pp. 412-416, 2004.

[15] M. Martinez-Agirre and M. J. Elejabarrieta, "Dynamic characterization of high damping viscoelastic materials from vibration test data," Journal of Sound and Vibration, vol. 330, no. 16, pp. 3930-3943, 2011.

[16] S.-Y. Kim and D.-H. Lee, "Identification of fractionalderivative-model parameters of viscoelastic materials from measured FRFs," Journal of Sound and Vibration, vol. 324, no. 3-5, pp. 570-586, 2009.

[17] O. T. Easterday, A. N. Palazotto, W. P. Baker, R. D. Branam, and T. George, "Experimental characterization of damping properties of coatings at elevated temperatures using a free-free beam based apparatus," in Proceedings of the 52nd AIAA/ ASME/ASCE/AHS/ASC Structures, Structural Dynamics and Materials Conference, Denver, Colo, USA, April 2011.

[18] M. Friswell and J. E. Mottershead, Finite Element Model Updating in Structural Dynamics, Springer Science \& Business Media, 1995. 
[19] J. E. Mottershead, M. Link, and M. I. Friswell, “The sensitivity method in finite element model updating: a tutorial," Mechanical Systems and Signal Processing, vol. 25, no. 7, pp. 2275-2296, 2011.

[20] G. Parthasarathy, C. V. R. Reddy, and N. Ganesan, "Partial coverage of rectangular plates by unconstrained layer damping treatments," Journal of Sound and Vibration, vol. 102, no. 2, pp. 203-216, 1985.

[21] W. Sun, H. Li, and Y. Liu, "Damping identification for the nonlinear stiffness structure," Journal of Vibroengineering, vol. 16, no. 2, pp. 981-991, 2014. 

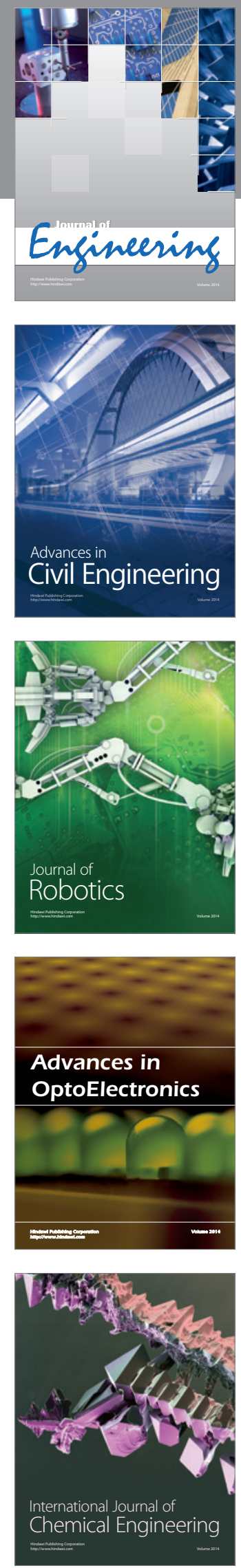

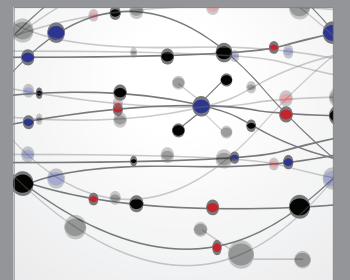

The Scientific World Journal
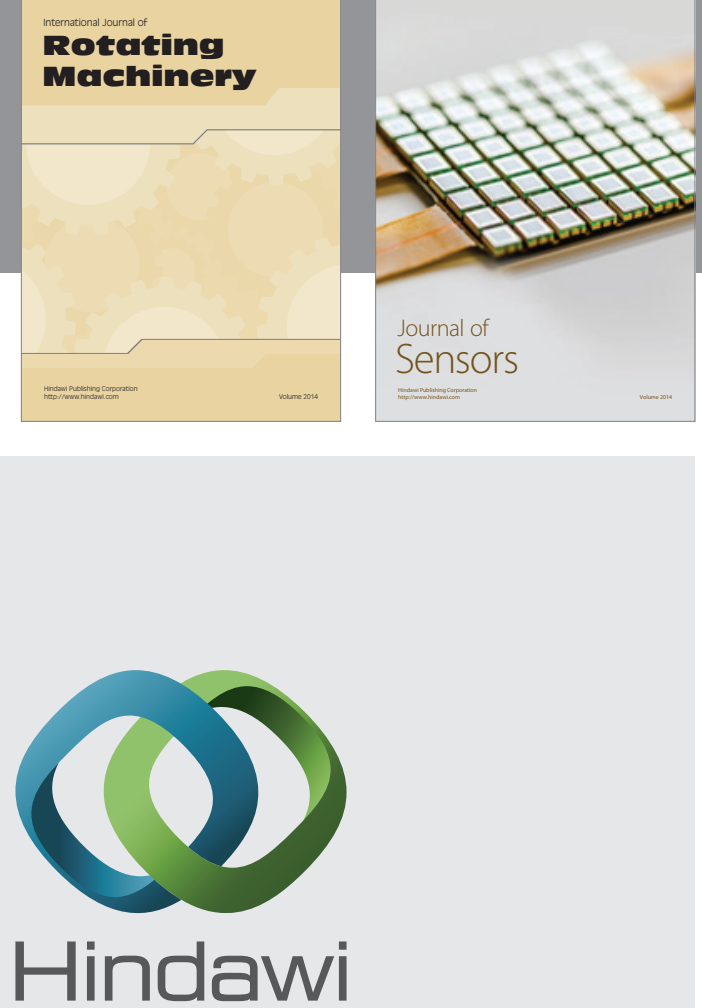

Submit your manuscripts at http://www.hindawi.com
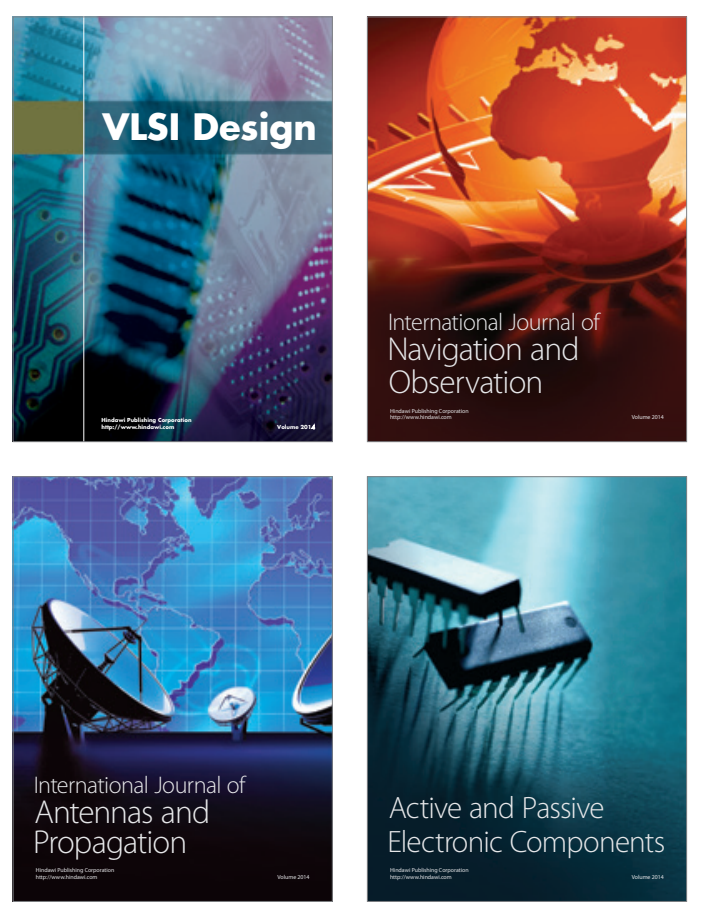
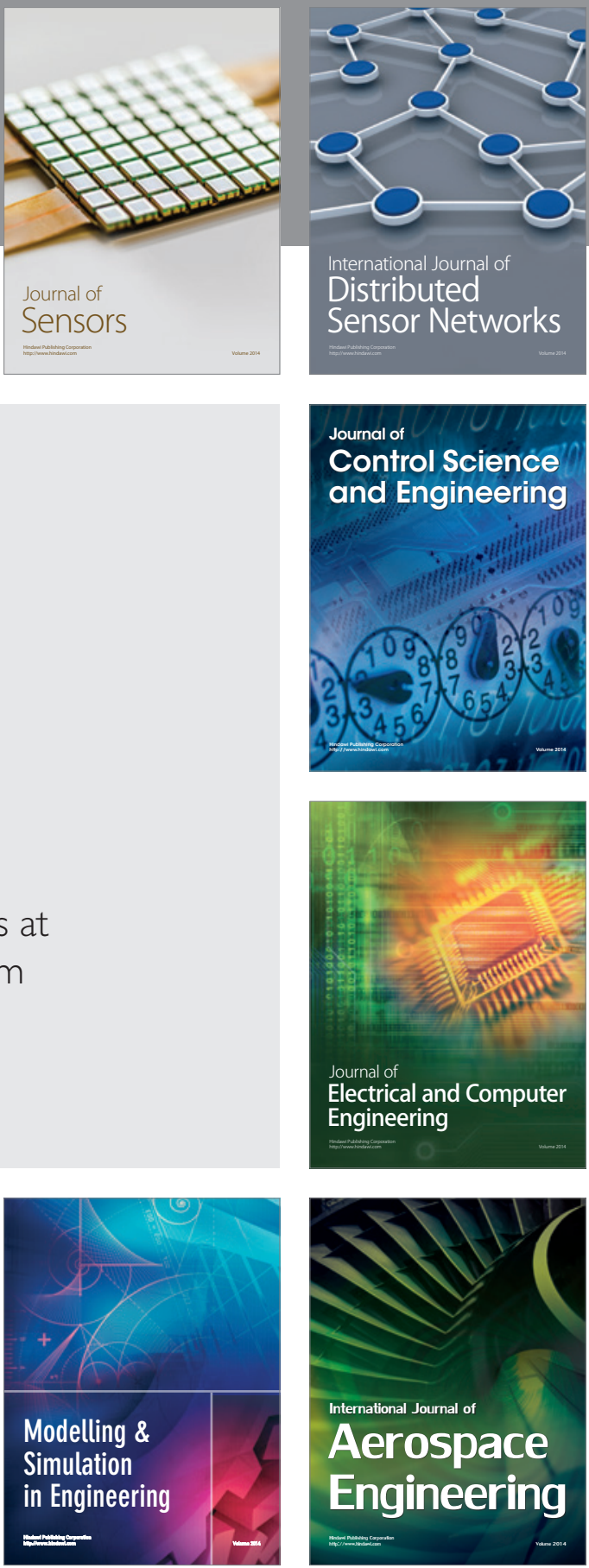

Journal of

Control Science

and Engineering
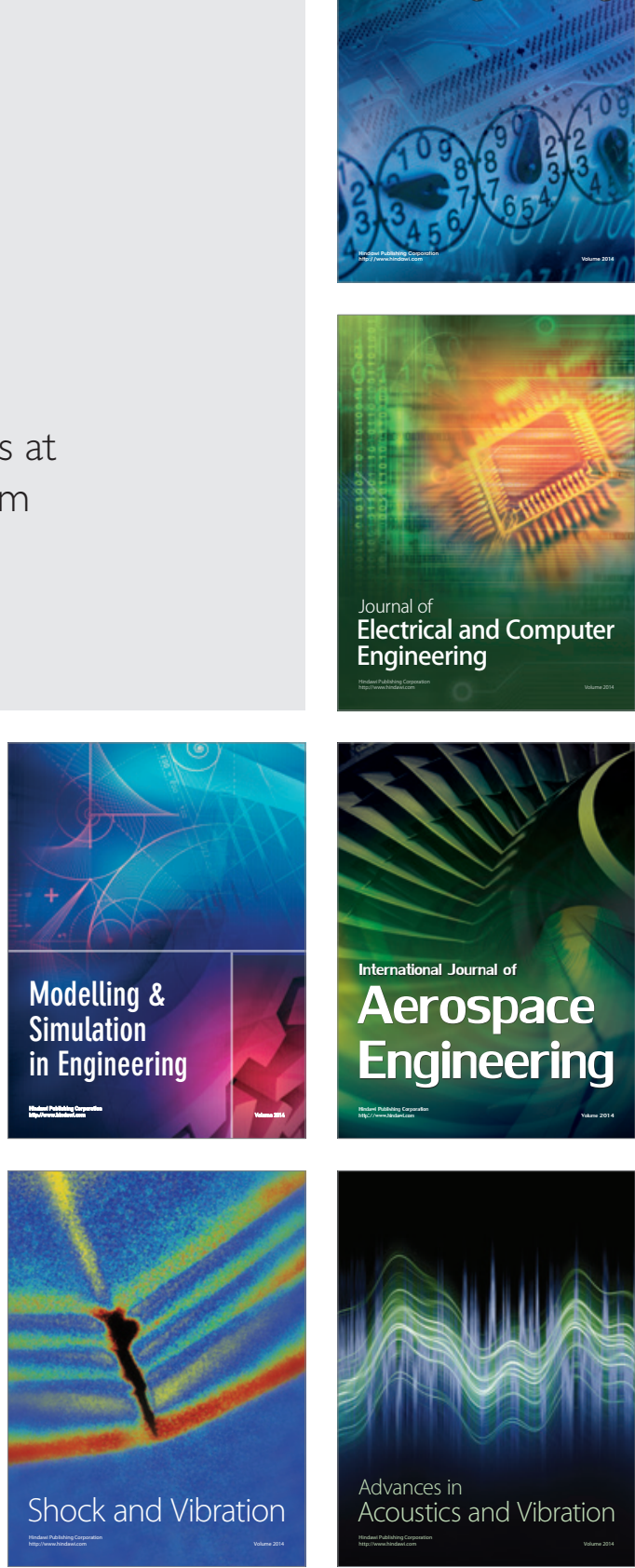